\title{
A study of various heating effects on the microstructure and mechanical properties of AA6082 using EBSD and CPFE
}

\author{
Zhutao Shao ${ }^{\text {a }}$, Junyi Lee ${ }^{\text {a }}$ Jianglong Wang ${ }^{\text {a }}$, Jianguo Lin ${ }^{\text {a }}$, Jun Jiang ${ }^{\text {a,* }}$ \\ ${ }^{a}$ Department of Mechanical Engineering, Imperial College London, London SW7 2AZ, UK
}

\begin{abstract}
The solution heat treatment (SHT) process resolving hardening precipitates in high strength aluminium alloys is a critical step for high-efficient forming processes, such as Hot Form Quench $\left(\mathrm{HFQ}^{\circledR}\right)$. SHT largely determines the overall cycle time of a forming process. However, effects of heating process parameters, such as the heating rate and soaking time, on the microstructure and the associated mechanical properties of aluminium alloy 6082, one of the most commonly used aluminium alloys, for HFQ applications have not been systematically investigated. The aim of this study is to explore and understand the relationships among heat treatment conditions, grain microstructure and associated mechanical properties for AA6082. A series of uniaxial tensile tests conducted under various SHT conditions revealed significant variation on mechanical behaviour characterised by stress-strain curves. To correlate these stressstrain relationship with underlying microstructure, the grain and orientation distribution of each heat-treated sample were characterised by the electron backscatter diffraction (EBSD) technique. Due to the presence of a large number of microscopic variables, such as grain size, morphology, texture, grain boundary and etc., the crystal plasticity finite element (CPFE) modelling was employed to identify the key microscopic factors which determine the differences in the observed strength and ductility for all samples. A new CPFE model integrated with local strain criterion was proposed and validated to correlate the ductility and the strength with the material microstructure. This rigorous investigation provides more insights on how microstructure (grain size and texture) affects the mechanical behaviour for AA6082, which enables to enlarge the capability of HFQ for industrial applications.
\end{abstract}

Keywords Solution heat treatment, Microstructure evolution, Aluminium alloy 6082, Crystal plasticity finite element

${ }^{*}$ Corresponding author.

E-mail address: jun.jiang@imperial.ac.uk (J. Jiang). Tel: +44(0)20 75947175 


\section{Introduction}

Weight reduction has gained popularity as a subject of research and development in the transportation industries in the pursuit to minimise energy consumption. A weight reduction of $10 \%$ will lead to fuel savings of $6 \%$ to $8 \%$ for a conventional vehicle, and a 30\% weight reduction can be achieved by replacing the steel components in automobiles with aluminium alloys [1]. However, aluminium alloys, usually have low formability in cold forming operations, which impedes the ability to form complexshaped components at room temperature [2]. A state-of-the-art material hot forming process, known as Hot Form Quench (HFQ), has been developed as a disruptive technique to overcome this limitation to form complex-shaped high strength aluminium components $[3,4]$.

In a typical HFQ process, a heat treatable aluminium sheet is heated to the solution heat treatment temperature at which a solid solution with a single phase is achieved. The sheet is then transferred to a press, formed and quenched simultaneously in a cold tool $[5,6]$. The control of forming conditions, such as heating rate, soaking time at the solution heat treatment (SHT) temperature, quenching rate, forming speed and forming temperature is crucial for the success of these processes [7]. The patented HFQ technique has been commercialised to form deep-drawn complex-shaped components in the automotive and aircraft industries [8]. During HFQ, sufficient heating and soaking processes are required in this technique so that a super-saturated solid solution can be achieved, which is beneficial to improving formability [9]. However, the current slow heating rate of about $3{ }^{\circ} \mathrm{C} / \mathrm{s}$ and long soaking time increase the costs and lower the productivity, and the effects of heating rate and soaking time on microstructure evolution in HFQ have not been investigated. Metal sheets undergo significant microstructural changes since the HFQ process is performed at elevated temperatures in order to improve material formability. Since there are few quantitative studies on the effect of heating parameters performed for hot aluminium forming processes, the microstructure evolution and its impact on the mechanical properties remain unclear under various HFQ conditions, which increases the uncertainty of practical control of the HFQ forming parameters. Also, the variation of temperature in a metal sheet needs to be controlled accurately according to the process requirements for advanced applications, which should be based on the in-depth understanding of the effects of 
heating process parameters on material properties instead of using the trial and error method.

In the previous study, Shao et al. $[10,11]$ determined the mechanical properties of aluminium alloy 6082 under HFQ conditions, but the microstructure evolution was not analysed accordingly. Poletti et al. [12] studied the microstructure changes of AA6082 and the misorientation distribution and recrystallised conditions were analysed for hot extruded and hot rolled samples, but not for hot forming applications. Moy et al. [13] studied the effect of precipitation hardening on mechanical properties and formability of AA2024 and found that the ageing time is critical for material formability at difference strain state conditions. Crystallographic textures of aluminium alloys are dependent on the material processing method, materials chemical compositions and heat treatment processes. Textures of polycrystalline aluminium alloys are critical factors because they determine the materials anisotropy, and texture analysis can be used to study the mechanism of microstructure evolution. Wang et al. [14] studied the effects of solution time on texture and mechanical properties of aluminium alloys with different contents of iron-rich phase. They found that recrystallisation and the texture of aluminium alloys were strongly affected by solution time, recrystallisation and the dissolution of particles occurred at early stages of SHT for as-rolled alloys. Lopes et al. [15] explained the anisotropy in strain hardening for AA1050-O by the dominant factor of texture and evolution with strain. Lademo et al. [16] used the Marciniak-Kuczynski (M-K) theory [17] to study the effect of texture on the formability for aluminium 7000 materials at room temperature and concluded that strongly textured alloys exhibit inferior formability compared to alloys with weak or nearly random texture due to reduced work hardening. Pedersen et al. [18] investigated the effect of grain structure and texture on formability and strain localisation for AA6063 and AA6082 in temper W by using M-K model as well. But the M-K method was found to provide conservative predictions of the formability for AA6082. Shabadi et al. [19] found that crystallographic texture affects strongly mechanical properties, at room temperature, of AA7020 in terms of plastic flow and ductility but not yield strength, tensile strength and work hardening ability. Most of studies focused on the microstructure evolution for applications to various rolling, extrusion forming processes or welding [20, 21], and the material heat treatment processes without manufacturing applications. In HFQ, 
aluminium alloys at T4 or T6 conditions (solution heat treated and aged) with relatively fine precipitates [22] are usually used as original materials to reduce forming cycle time

[7]. Heat treatable aluminium alloy 6082 is extensively used in the automotive industry for forming vehicle bodies [23], and it has been used in mass production with HFQ forming. However, there is no systematic study available on the effects of heating processes for aluminium alloys on mechanical and microstructural properties under complex hot forming conditions.

Since the heat treatment process in HFQ significantly affects the texture changes and grain growth which directly affect the strength and formability of the sheet metal, the impact of the microstructure evolution on the mechanical properties needs to be invesitigated. The aim of this study is to quantify the effects of critical heating parameters on both material strength and ductility, characterised by uniaxial tensile tests, and corresponding microstructure evolution, obtained by electron backscatter diffraction (EBSD), and to correlate the deformation mechanism of the material with microstructure evolution by using a crystal plasticity finite element (CPFE) model for important practical applications and parameter optimisations in the HFQ processes.

\section{Experimental programme}

\subsection{Material and specimen}

As-rolled AA6082 of T6 temper with fine precipitates [24] was used in this study to replicate the HFQ heat treatment conditions. The chemical compositions [3] of AA6082 are shown in Table 1, and the elongation of the material is about $12 \%$ at room temperature.

Table 1 The chemical compositions of AA6082

\begin{tabular}{ccccccccccc}
\hline Element & $\mathrm{Si}$ & $\mathrm{Fe}$ & $\mathrm{Cu}$ & $\mathrm{Mn}$ & $\mathrm{Mg}$ & $\mathrm{Cr}$ & $\mathrm{Zn}$ & $\mathrm{Ti}$ & $\mathrm{Al}$ \\
\hline $\begin{array}{c}\text { Weight } \\
\text { proportion (\%) }\end{array}$ & 0.90 & 0.38 & 0.08 & 0.42 & 0.70 & 0.02 & 0.05 & 0.03 & Balance \\
\hline
\end{tabular}


The dimensions of the dog-bone specimen used in the mechanical tensile tests are shown in Fig. 1, which was designed according to international standards ISO 68921:2009 [25]. The width and the thickness are $6 \mathrm{~mm}$ and $1.5 \mathrm{~mm}$, respectively. The nominal length of the parallel gauge section is $32 \mathrm{~mm}$, and the rolling direction is parallel to the gauge section.

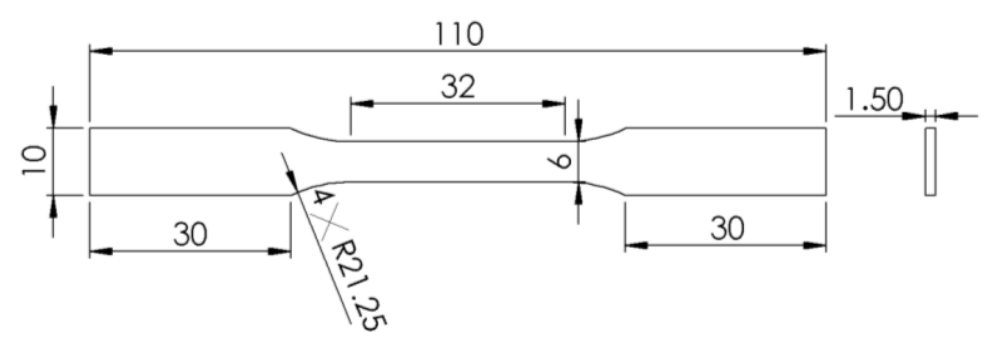

Fig. 1. Dimensions (mm) of dog-bone specimens used in this study

\subsection{Heating and cooling processes}

A pair of K-type thermocouples was attached to the side of the specimen along the width direction and connected to a data logger to monitor the temperature history during the entire heating and cooling processes. In order to achieve a rapid heating rate, two metal blocks, using for fast conductive heating through clamping samples, were preheated to a target temperature within a thermal furnace. The temperature profile of the heating and cooling processes for AA6082 under HFQ conditions is shown in Fig. 2 and the test condition matrix is presented in Table 2 with a total of 6 including the asreceived condition.

The material was heated to the solution heat treatment temperature of $535{ }^{\circ} \mathrm{C}$ at a rapid heating rate of $36{ }^{\circ} \mathrm{C} / \mathrm{s}$, and at a slow heating rate of $3{ }^{\circ} \mathrm{C} / \mathrm{s}$, respectively. Once the temperature of the specimen reached the programmed value, various soaking time was selected for the solution heat treatment in the range of $1 \mathrm{~s}$ to $10 \mathrm{~min}$. The specimens were subsequently water quenched to maintain the material microstructure without grain degradation in the material. A standard ageing process of $9 \mathrm{~h}$ at $190{ }^{\circ} \mathrm{C}$ was then applied to all of the heat-treated samples of AA6082 in order to keep consistency and to simulate a complete cycle of HFQ [26]. The effect of ageing time on material microstructure is not studied in this work since the ageing process is a standard process for heat-treatable alloys in HFQ processes. 


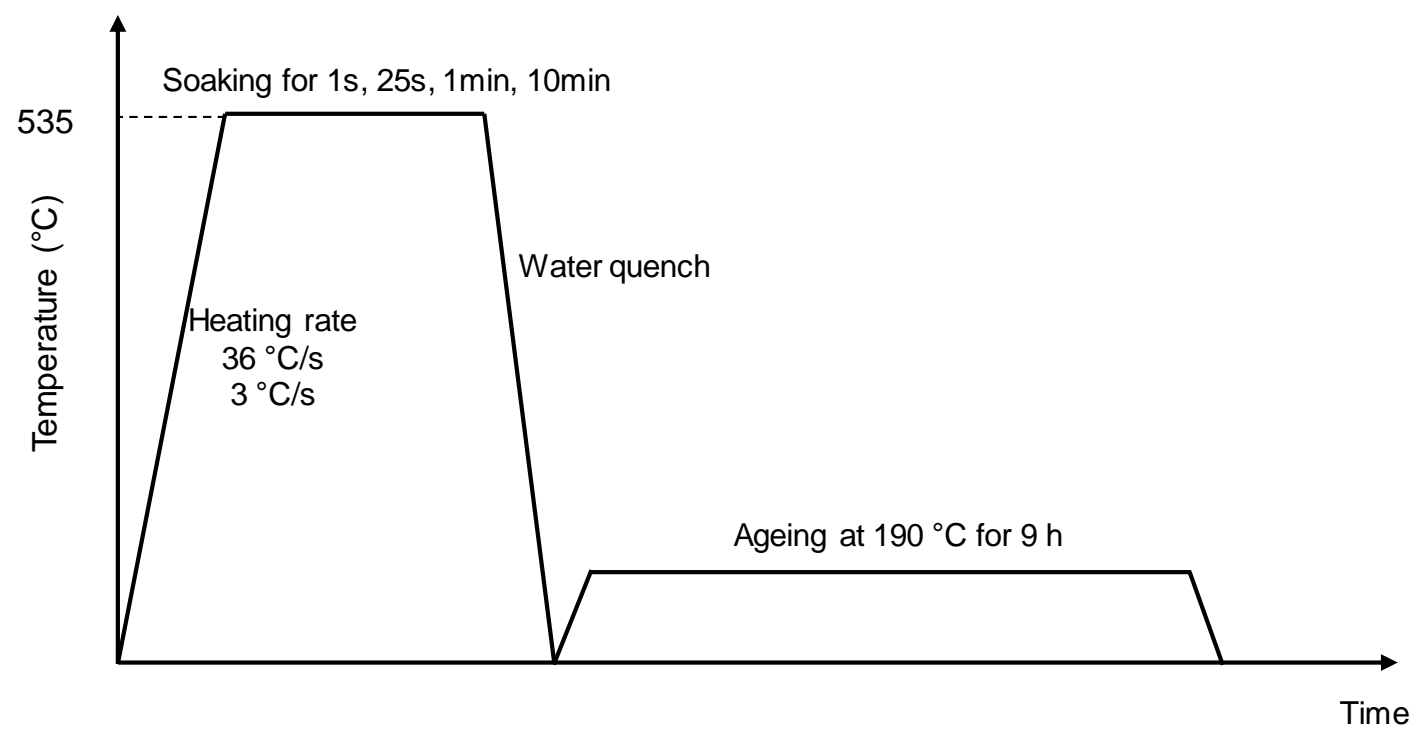

Fig. 2. Temperature profile of heating and cooling processes for AA6082 under HFQ conditions

Table 2 Test matrix of heat treatment conditions used in this study

\begin{tabular}{llllll}
\hline & \multicolumn{5}{c}{ Soaking time (s) } \\
\cline { 3 - 5 } & & 1 & 25 & 60 & 600 \\
\hline $\begin{array}{c}\text { Heating } \\
\text { rate } \\
\left({ }^{\circ} \mathrm{C} / \mathrm{s}\right)\end{array}$ & 3 & $\sqrt{ }$ & & & \\
\hline
\end{tabular}

\subsection{Testing procedures of tensile test and EBSD}

The uniaxial tensile tests were conducted by using the Instron machine to obtain the stress-strain curves of all samples heat treated under various conditions designated in Table 2. The tensile test procedure conforms to the ISO 6892-1:2009 standard and is conducted at room temperature at least three times to ensure the repeatability of the result measurement (difference is controlled within 5\%). After uniaxial tensile test, materials from the clamping region without being deformed were cut off from the dogbone specimens, and they were mechanically ground and polished with Oxide Polishing Suspension (OPS) to a mirror finish and then ion-etched with a Gatan PECS machine at the voltage of $3.5 \mathrm{keV}$ for half an hour. The obtained grain microstructure maps from 
the EBSD tests by using the software of Esprit were then analysed for each individual tested sample and the corresponding results from microstructure analysis were used to quantify the effects of heating parameters, namely heating rate and solution time at the SHT temperature, on material strength and ductility of AA6082. The trends obtained from the experimental data analysis will be correlated with the quantified microstructure evolution by the CPFE models established in this work. Fine precipitates were observed for samples, and the effect on precipitate is for future study.

\section{The crystal plasticity modelling and microstructural analysis method}

\subsection{Crystal plasticity model used for microstructural analysis}

CPFE analysis was used to study the deformation behaviour of the material on a microstructural level in order to correlate the effects of the grain microstructure and texture with the mechanical properties of AA6082 heat treated under various HFQ conditions. CPFE models take into account the individual slip systems of a crystal, allowing it to capture the effect of plastic anisotropy and the effect of crystallographic texture [27]. Ma et al. [28] and Evers et al. [29]'s CPFE models are also able to capture size-dependent effects and interface effect, and can be used for studying the effect of microstructure evolution. The CPFE model adopted in this research is based on previous studies [30,31], and this model takes into account key mechanisms that influence the mechanical properties of the material, including the individual slip systems, geometrically necessary dislocations (GND), and statically stored dislocations (SSD).

The constitutive model of the material is given as follows.

$$
\sigma_{i j}=C_{i j k l} E_{k l}^{E}=\frac{1}{2} C_{i j l k}\left(\mathrm{~F}_{k i}^{E} \mathrm{~F}_{k j}^{E}-\delta_{i j}\right) \quad \text { Eq. } 1
$$

where $\sigma_{i j}$ is the stress, $C_{i j k l}$ is the elastic tensor, $E_{k l}^{E}$ is the elastic component of the Green strain tensor, $\mathrm{F}_{k i}^{E}, \mathrm{~F}_{k j}^{E}$ are the elastic components of the deformation gradient, and $\delta_{i j}$ is the Kroneker delta.

The total deformation gradient, $\mathrm{F}_{i j}$, is decomposed into the elastic, $\mathrm{F}_{i j}^{E}$, and plastic components, $\mathrm{F}_{i j}^{P}$ [32]. 


$$
\mathrm{F}_{i j}=\mathrm{F}_{i j}^{E} \mathrm{~F}_{i j}^{P}
$$

The plastic velocity gradient, $L_{i j}^{P}$, can then be defined.

$$
L_{i j}^{P}=\dot{\mathrm{F}}_{i k}^{P}\left(\mathrm{~F}_{k j}^{P}\right)^{-1}=\sum_{\alpha} \dot{\gamma}^{\alpha} s_{i}^{\alpha} n_{j}^{\alpha}
$$

where $\dot{\gamma}$ is the slip rate, $s_{i}$ is the line vectors along the slip direction, and $n_{j}$ is the normal to the slip plane, and $\alpha$ denotes the slip system.

Aluminium alloy has a face centred cubic (FCC) crystal structure with a total of 12 slip systems. The slip rate in this study is expressed by the Orowan equation.

$$
\dot{\gamma}^{\alpha}=\rho_{S S D M} b v^{\alpha}
$$

Eq. 4

where $\rho_{S S D M}$ is the mobile dislocation density, $b$ is the magnitude of the Burger's vector, and $v^{\alpha}$ is the velocity of the dislocations defined as below.

$$
v^{\alpha}=\left\{\begin{array}{cc}
b f \exp \left(-\frac{\Delta F}{k_{B} T}\right) \sinh \left(\frac{\left(\left|\tau^{\alpha}\right|-\tau_{c}^{\alpha}\right) \gamma_{0} \Delta V^{\alpha}}{k_{B} T}\right) \cdot \operatorname{sign}\left(\tau^{\alpha}\right) & \text { if }\left|\tau^{\alpha}\right|>\tau_{c}^{\alpha} \quad \text { Eq. } 5 \\
0 & \text { otherwise }
\end{array}\right.
$$

where $b$ is the magnitude of the Burger's vector, $f$ is the jump frequency for driving thermally activated dislocation escape, $\Delta F$ is the Helmholtz free energy, $k_{B}$ is the Boltzmann constant, $T$ is the temperature, $\tau^{\alpha}$ is the resolved shear stress, $\tau_{c}^{\alpha}$ is the critical resolved shear stress, $\gamma_{0}$ is a material parameter, and $\Delta V^{\alpha}$ is the activation volume.

$$
\begin{gathered}
\tau^{\alpha}=s_{i}^{\alpha} \sigma_{i j} n_{j}^{\alpha} \\
\tau_{c}^{\alpha}=\tau_{c o}^{\alpha}+a G_{12} b \sqrt{\rho_{G}+\rho_{S}} \\
\Delta V^{\alpha}=\frac{b^{2}}{\sqrt{\psi\left(\rho_{s}+\rho_{G}\right)}}
\end{gathered}
$$

where $\psi$ is a coefficient, $\rho_{S}$ is the statically stored dislocation density, $\rho_{G}$ is the geometrically necessary dislocation density, $\tau_{c o}^{\alpha}$ is the initial critical shear stress, and $a$ is a material parameter. 
The evolution of the statically stored dislocation density is calculated as follows.

$$
\dot{\rho}_{S}=\lambda \sqrt{\frac{2}{3} D_{i j}^{P} D_{i j}^{P}}
$$

where $\lambda$ is the hardening coefficient, and $D_{i j}^{P}$ is the symmetric rate of plastic deformation determined by $D_{i j}^{P}=\operatorname{sym}\left(L_{i j}^{P}\right)$.

The GND density is calculated using the Nye's dislocation tensor $\Lambda$, based on Arsenlis's work [33]. The Nye's dislocation tensor is able to be calculated.

$$
\begin{array}{cl}
\Lambda=\epsilon_{i j k} \nabla_{j} \mathrm{~F}_{k l}^{\mathrm{P}}=\sum_{\alpha} \rho_{G s}^{\alpha} b_{i}^{\alpha} s_{j}^{\alpha}+\rho_{G e t}^{\alpha} b_{i}^{\alpha} t_{j}^{\alpha}+\rho_{G e n}^{\alpha} b_{i}^{\alpha} n_{j}^{\alpha} & \text { Eq. } 10 \\
t_{i}^{\alpha}=\epsilon_{i j k} s_{j}^{\alpha} n_{k}^{\alpha} & \text { Eq. } 11
\end{array}
$$

where $\epsilon_{i j k}$ is the Levi-Civita symbol, $\rho_{G S}^{\alpha}$ is the screw dislocation density, $\rho_{\text {Get }}^{\alpha}$ is the edge dislocation density, $\rho_{G e t}^{\alpha}$ is the tangential component of the edge dislocation density, and $\rho_{G e n}^{\alpha}$ is the normal component of the edge dislocation density.

In order to compute the 36 independent GND components of the FCC crystal, Eq. 10 can be recast as follows.

$$
\begin{gathered}
A \rho_{G}=\Lambda \\
\rho_{G}=A^{+} \Lambda
\end{gathered}
$$

where $\rho_{\mathrm{G}}$ is a vector of all the GND components, $A$ is a tensor formulated with the methodology from [34], and $A^{+}$is the pseudo-inverse of $A$.

The GND of each slip system can then be calculated.

$$
\rho_{G}=\sqrt{\rho_{G S}^{2}+\rho_{G e t}^{2}+\rho_{G e n}^{2}}
$$

The model was implemented in the commercial finite element analysis software, Abaqus, using a user-defined subroutine (UMAT). The material constants were 
calibrated, as listed in Table 3, based on the mechanical properties characterised by obtained stress-strain curves from uniaxial tensile tests for the as-received AA6082.

Table 3 Material constants used in the CPFE model

\begin{tabular}{lcc}
\hline Property & Value & Unit \\
\hline Young's Modulus & 70 & $\mathrm{GPa}$ \\
Poisson's ratio & 0.35 & - \\
Mobile dislocation density, $\rho_{S S D M}$ & 0.01 & $\mu \mathrm{m}^{-2}$ \\
The magnitude of the Burger's vector, $b$ & $2.86 \times 10^{-4}$ & $\mu \mathrm{m}$ \\
Attack frequency, $f$ & $1.0 \times 10^{-11}$ & $\mathrm{~s}^{-1}$ \\
Helmholtz free energy, $\Delta F$ & $2.9 \times 10^{-20}$ & $\mathrm{~J}$ \\
Temperature, $T$ & 297.15 & $\mathrm{~K}$ \\
Initial critical resolved shear stress, $\tau_{c o}$ & 113.9 & $\mathrm{MPa}$ \\
Material parameter, $\gamma_{0}$ & $6.0 \times 10^{-4}$ & $\mathrm{Jm}^{-3}$ \\
Material parameter, $a$ & 0.22 & - \\
Coefficient $\psi$ & 1.0 & - \\
Hardening coefficient $\lambda$ & 1.5 & $\mu m^{-2}$ \\
\hline
\end{tabular}

\subsection{The setup of the CPFE model}

In order to import the EBSD map into the CPFE model, the EBSD information was first processed using the MTEX toolbox [35] to identify each individual grain and their orientations in the microstructure, and then a mesh with the same size as that of the EBSD map is generated with hexahedral elements (C3D8) with a thickness of $9 \mu \mathrm{m}$ and length of $3 \mu \mathrm{m}$ in the CPFE model. The section properties of each element were set to the values based on the EBSD information. The parameters presented in Table 3 were identical for all elements with the values of the slip direction and slip normal being set based on the orientation of each crystal. The comparison of the grain microstructure of as-received material obtained from EBSD and the microstructure model with boundary conditions used in the finite element analysis are shown in Fig. 3 (a) and (b), respectively. The CPFE analysis was then performed for each sample tested under various HFQ conditions to investigate the effects of heating process. 
(a)

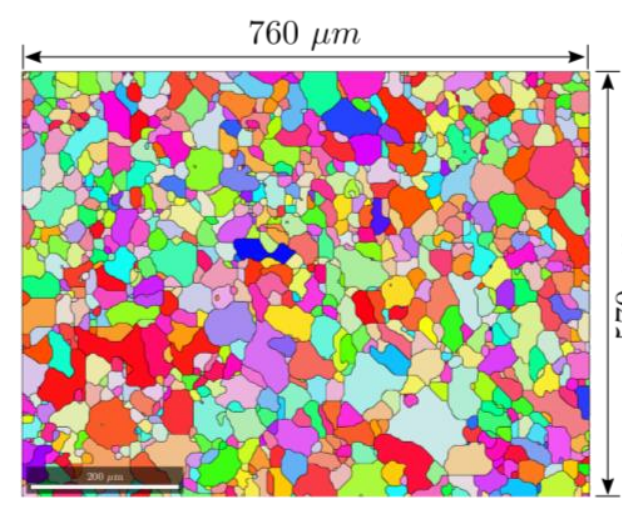

(b)

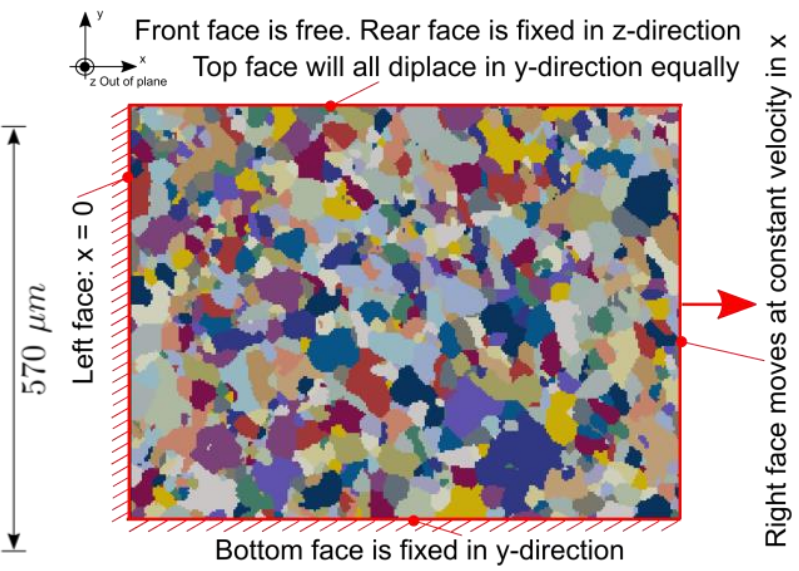

Fig. 3. An example of CPFE model setup for AA6082 of as-received condition (a) microstructure characterisation from EBSD (b) Converted microstructure and boundary conditions in the CPFE model

\subsection{Data processing for microstructural analysis}

The effects of grain size, grain distribution and texture on mechanical properties are investigated and quantified by EBSD and CPFE simulation results. Although texturing will result in changes in the strength and overall deformation behaviour of the material, a method to quantify the strength of each grain under the loading conditions imposed is crucial in the analysis. In the CPFE models, the samples are loaded in the $\mathrm{x}$-direction (the gauge and material rolling direction) where the strains are highest in this direction, which was consistent with the loading direction in uniaxial tensile tests for the same dog-bone specimen. The major stress and major strain are presented as $\sigma_{11}$ and $E_{11}$, respectively. When the grains yield, the softness of the grains under this loading condition can be determined by investigating the plastic strain rate, $L_{11}^{P}$. The plastic strain rate, when the strength is $5 \%$ above the yield stress, $\sigma_{y}$, of the material, was used to determine the softness of the grains in the CPFE model. The softness parameter, $S$, can then be determined by substituting Eq. 4 and Eq. 6 into Eq. 3.

$$
\begin{gathered}
S=L_{11}^{P}\left(\sigma_{11}=1.05 \sigma_{y}\right)=\sum_{\alpha} \dot{\gamma}^{\alpha} \hat{S}_{1}^{\alpha} \hat{n}_{1}^{\alpha} \\
=\sum_{\alpha} \rho_{S S D M} b^{2} f \exp \left(-\frac{\Delta F}{k_{B} T}\right) \sinh \left(\frac{\left(\left|\hat{S}_{1}^{\alpha}\left(1.05 \sigma_{y}\right) \hat{n}_{1}^{\alpha}\right|-\tau_{c}^{\alpha}\right) \gamma_{0} \Delta V^{\alpha}}{k_{B} T}\right) \cdot \operatorname{sign}\left(\hat{S}_{1}^{\alpha}\left(1.05 \sigma_{y}\right) \hat{n}_{1}^{\alpha}\right)
\end{gathered}
$$


where $\hat{s}_{i}^{\alpha}$ and $\hat{n}_{j}^{\alpha}$ are the slip and normal directions of the slip system after being rotated to the grain orientation, and the yield stress, $\sigma_{y}$, for an FCC crystal is calculated as follows.

$$
\sigma_{y}=\sqrt{6} \tau_{c}
$$

\section{Comparisons and discussions of experimental and CPFE simulation results}

\subsection{Determined stress-strain curves and correlated EBSD maps}

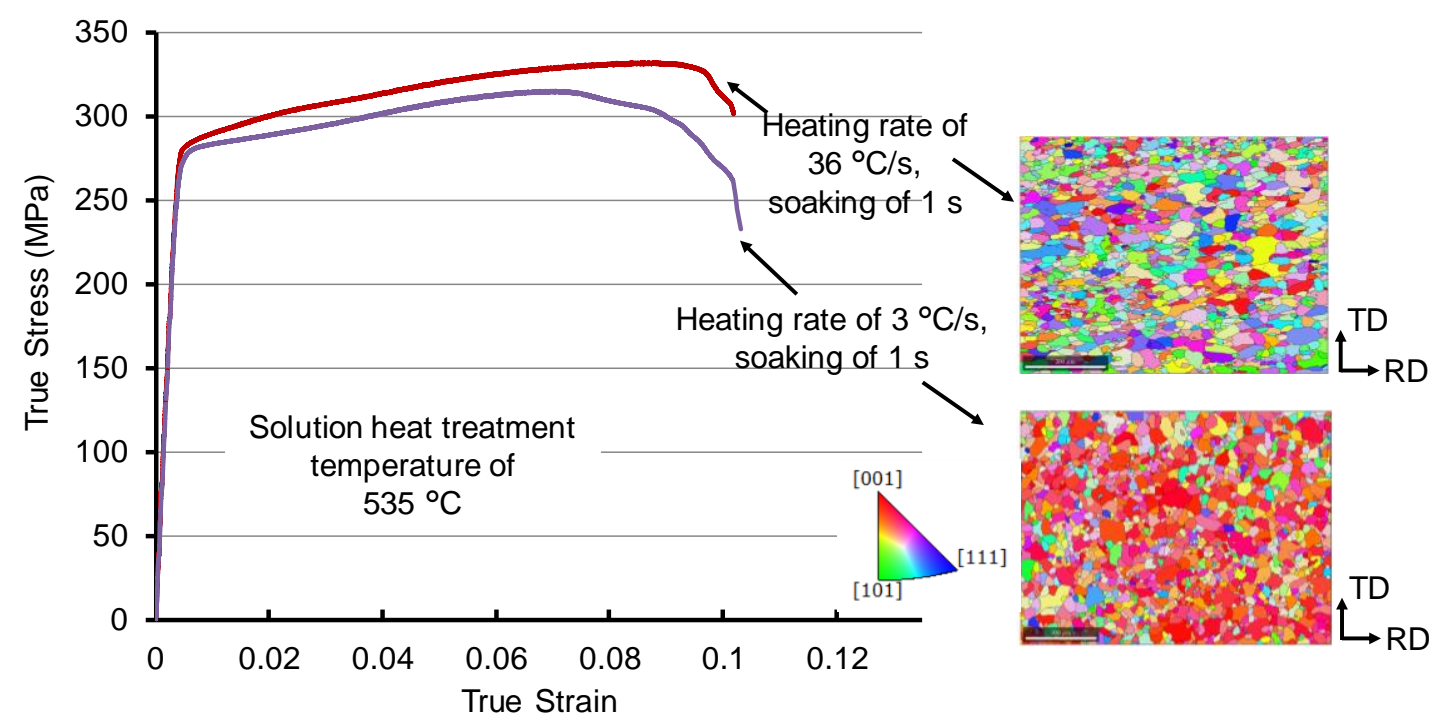

Fig. 4. Stress-strain curves and corresponding microstructure of AA6082 heat treated under fast and slow heating rate to the SHT temperature of $535^{\circ} \mathrm{C}$.

The effects of heating rate on mechanical properties and microstructure evolution of each AA6082 sample obtained by uniaxial tensile test and subsequent EBSD tests for each are shown in Fig. 4, in which, the three individual Euler angles are represented by each colour channel in EBSD maps. With a short solution time of $1 \mathrm{~s}$ at $535^{\circ} \mathrm{C}$, the ductility of the material was similar no matter what heating rate was selected. The stress level is slightly lower by using slow heating rate of $3{ }^{\circ} \mathrm{C} / \mathrm{s}$ for SHT, which means that high heating rate enables strength of AA6082 to be improved. According to the EBSD maps, quite random colour patterns can be seen for heat treated sample at fast heating rate of $36^{\circ} \mathrm{C} / \mathrm{s}$, which indicates that strong texture [36] was highly likely formed for the sample heat treated at slow heating rate of $3{ }^{\circ} \mathrm{C} / \mathrm{s}$. 
Stress-strain curves and microstructure of AA6082 heat treated by different soaking times at $535^{\circ} \mathrm{C}$ are determined in Fig. 5 after rapid heating at the heating rate of 36 ${ }^{\circ} \mathrm{C} / \mathrm{s}$. With the increase of soaking time from $1 \mathrm{~s}$ to $600 \mathrm{~s}$, the stress level of AA6082 reduced first at soaking time of up to $25 \mathrm{~s}$ and then increased, and the ductility was reduced by $25 \%$ for the sample with the longest soaking time of $600 \mathrm{~s}$, compared to that of others with slight difference.

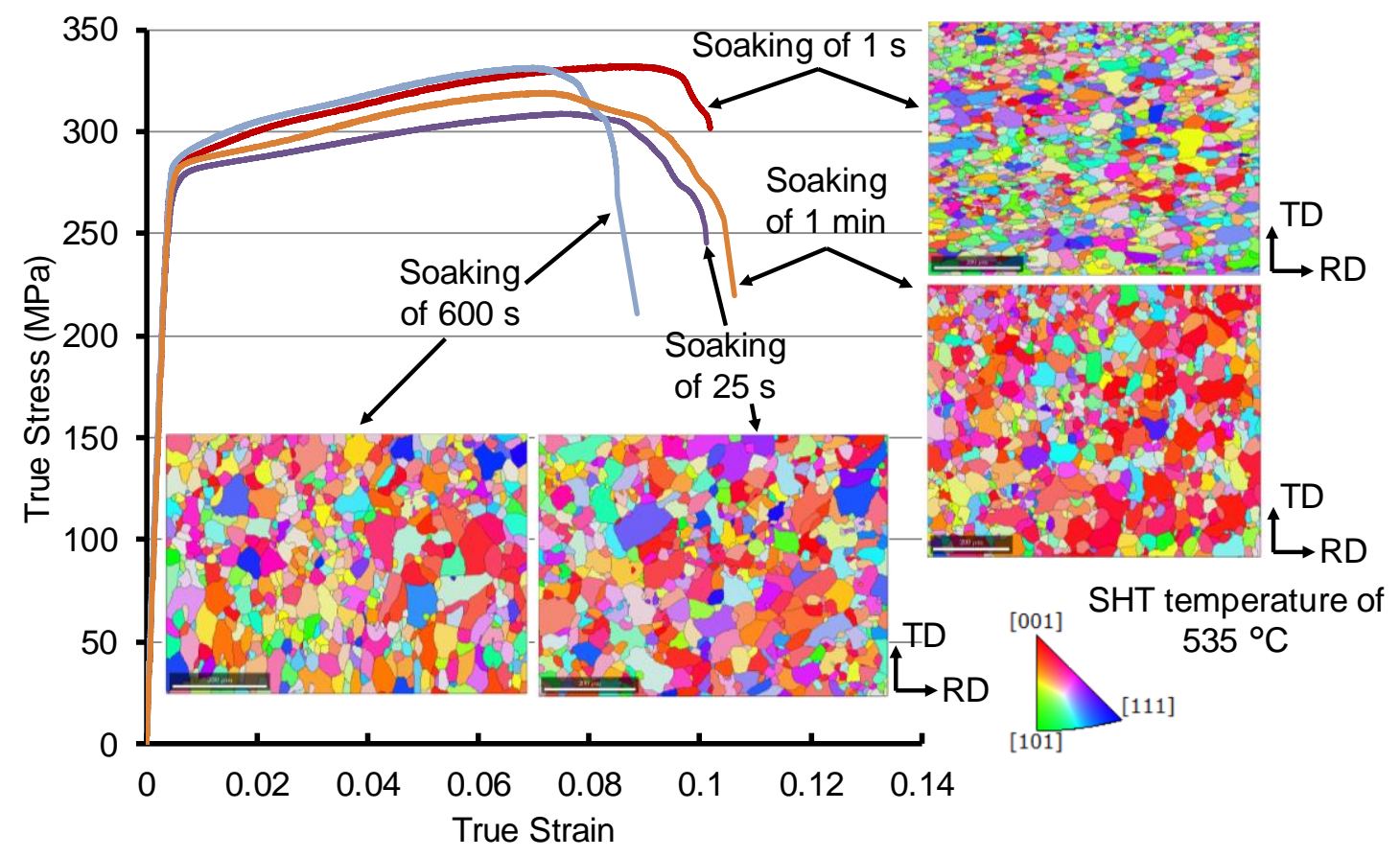

Fig. 5. Stress-strain curves and corresponding microstructure of AA6082 heat treated under different soaking times at the SHT temperature of $535^{\circ} \mathrm{C}$ after rapid heating.

According to the EBSD maps, the soaking process at $535^{\circ} \mathrm{C}$ for AA6082 resulted in significant changes in the microstructure compared to that of the material without soaking, as shown in Fig. 5. The heat-treated material has different grain sizes, and the orientation of the heat treated material appeared to be textured, which is illustrated by the lack of diversity in colours in EBSD maps, compared to that with a short soaking of $1 \mathrm{~s}$. Detailed study to quantify the grain size and the texture will be presented in Sections 4.3 and 4.4 .

\subsection{Characterisation of thermo-mechanical behaviour of AA6082}

The ductility of AA6082 was affected by the heating and soaking processes, and the strain to failure was measured, as shown in Fig. 6 (a). The symbols in Fig. 6 (a) indicate the values of strain to failure for AA6082 tested at different heating rates and different 
solution times, compared to the ductility of the as-received material. The strain to failure of AA6082 reduced slightly with increasing soaking time from $1 \mathrm{~s}$ to $25 \mathrm{~s}$, but by $17 \%$ at the long soaking time of $600 \mathrm{~s}$, which implies that the material formability would be potentially decreased during forming after the designated heat treatment processes in this study. The reasons for the reduction of ductility will be analysed on the microstructure level in Section 4.5.

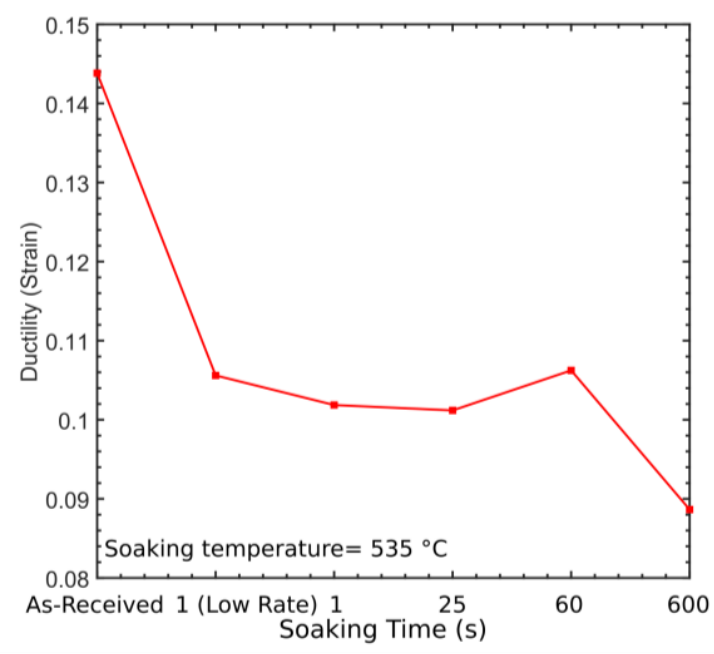

(a) Ductility of AA6082

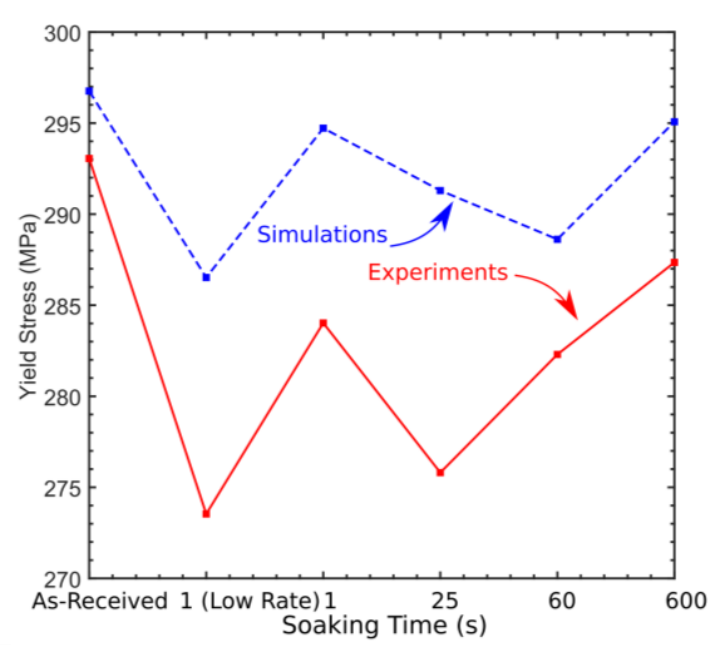

(b) Yield stress of AA6082

Fig. 6. Ductility (strain to failure) and yield stress of AA6082 for different heat treatment conditions

The effects of the heating rate and soaking time at the SHT temperature of $535^{\circ} \mathrm{C}$ on the yield stress of AA6082 has been quantified by analysing the $0.2 \%$ proof stress of the material, as shown in Fig. 6 (b). The solid lines represent the experimental data and dash lines were obtained by using the CPFE models introduced in Section 3. Ductile fracture during deformation is generally due to the nucleation, growth and coalescence of damage according to Nicolaou et al [37]. The simulation results overestimate the strength values of the alloys by about $5 \%$ since damage is not taken into account as a factor in the CPFE model. Similar trends of material strength can be observed between experimental results of uniaxial tensile tests and calculated results by the CPFE model. It was found that the yield stress of AA6082 was the lowest (7\% lower than that of asreceived) after heat treatment at the slow heating rate of $3{ }^{\circ} \mathrm{C} / \mathrm{s}$. With the increase of solution time from $1 \mathrm{~s}$ to $600 \mathrm{~s}$ at $535^{\circ} \mathrm{C}$ achieved by rapid heating at the rate of $36{ }^{\circ} \mathrm{C} / \mathrm{s}$, the strength of the material initially decreased and subsequently increased up to 285 
MPa for a soaking time of $600 \mathrm{~s}$. In general, the high flow stress level and relatively high strain hardening for AA6082 would be beneficial for material flow during drawing in of a forming process, and thus potentially increasing the formability of the material to form complex-shaped structural components; however, the negative effect of soaking time on ductility would also offset that positive effect of material stress level on material formability which is affected by both strain hardening and ductility of the material. The microstructure difference in terms of grain size and texture induced by heat treatment is possibly the main reason for the deterioration of mechanical properties of the material.

\subsection{Effects of grain size and grain distribution}

The grain boundary strengthening mechanism is commonly expressed by the HallPetch relationship [38] which states that the yield strength has an inverse relationship with the grain size. This means that a polycrystalline alloy with smaller grains would have a higher strength due to grain boundary strengthening. The average grain size for each condition, calculated by the MTEX toolbox, is plotted in Fig. 7 and the grain distributions are summarised in Fig. 8.

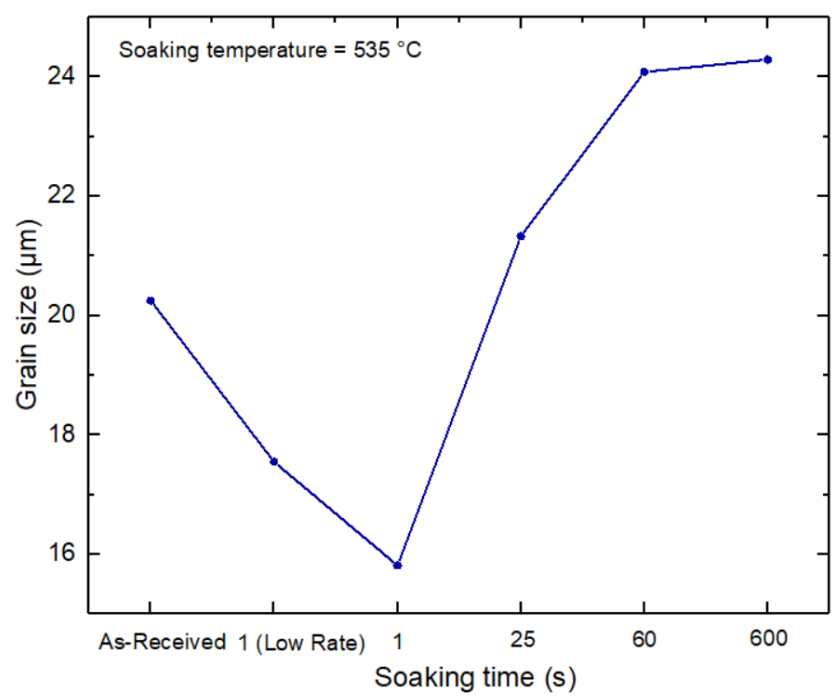

Fig. 7. The effects of heating rate and soaking time on average area of grain

The average grain size reduced $13 \%$ and $22 \%$, respectively for conditions of slow and fast heating rates, at the beginning of heat treatment at SHT temperature, due to the occurrence of recrystallisation indicated by the increase of small grains as shown in Fig. 8 (b) and (c). More uniform distribution of grains can be observed at the slow heating 
rate of $3{ }^{\circ} \mathrm{C} / \mathrm{s}$ compared to that at the rapid heating rate of $36^{\circ} \mathrm{C} / \mathrm{s}$, which implies that high heating rate with less heating time is able to reduce grain growth of recrystallisation in the AA6082, and a higher strength of the material is possibly to be obtained through rapid heating. This is consistent with the trend of material strength measured and indicated in Fig. 4.

(a) As-received material

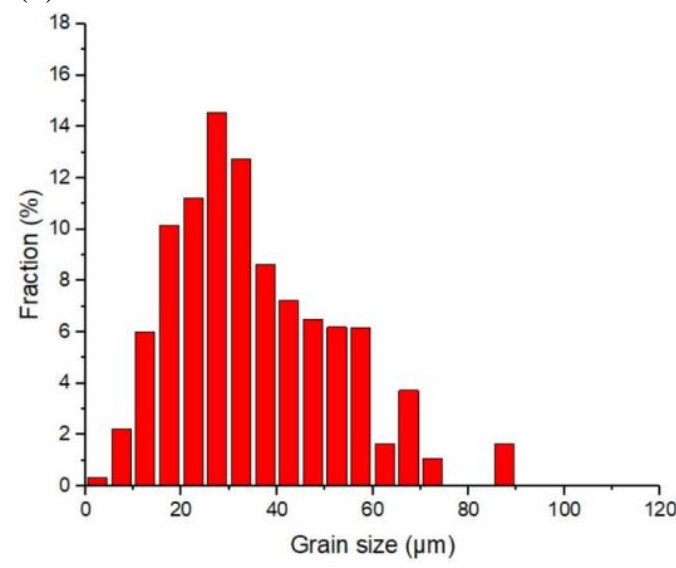

(c) $1 \mathrm{~s}$ of soaking after heating at $36^{\circ} \mathrm{C} / \mathrm{s}$

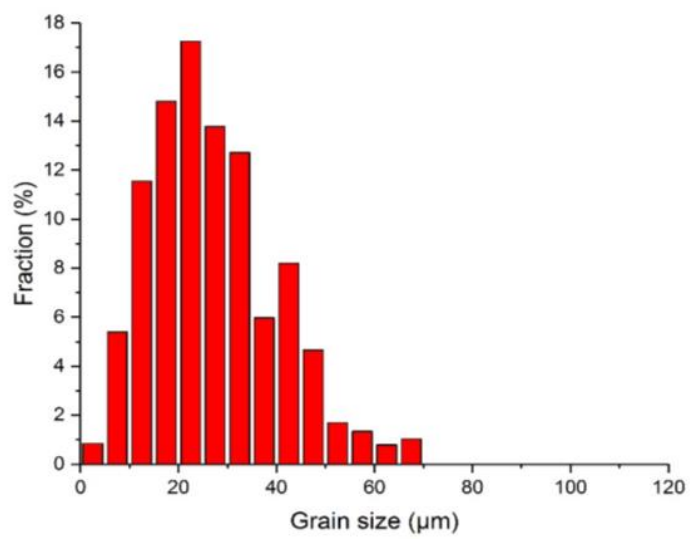

(e) $60 \mathrm{~s}$ of soaking after heating at $36^{\circ} \mathrm{C} / \mathrm{s}$

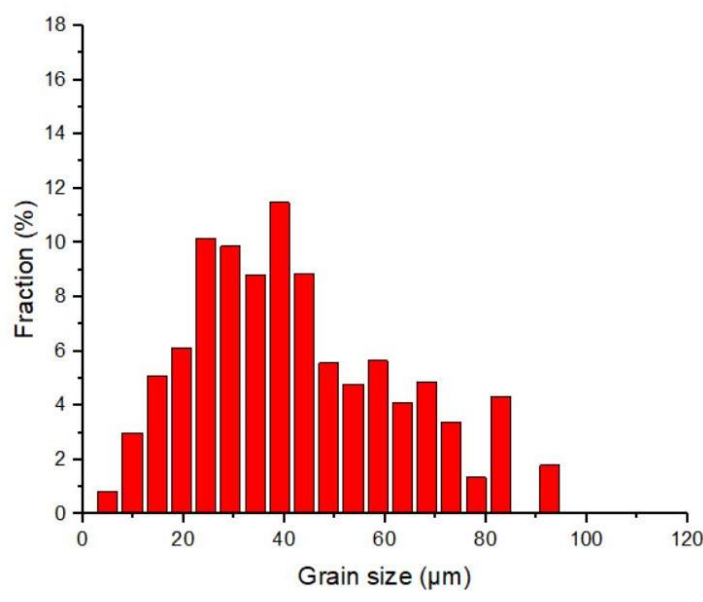

(b) $1 \mathrm{~s}$ of soaking after heating at $3{ }^{\circ} \mathrm{C} / \mathrm{s}$

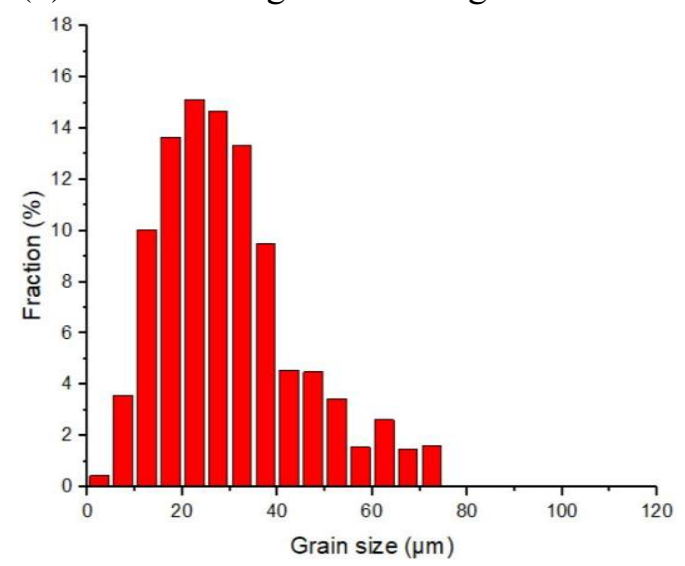

(d) $25 \mathrm{~s}$ of soaking after heating at $36{ }^{\circ} \mathrm{C} / \mathrm{s}$

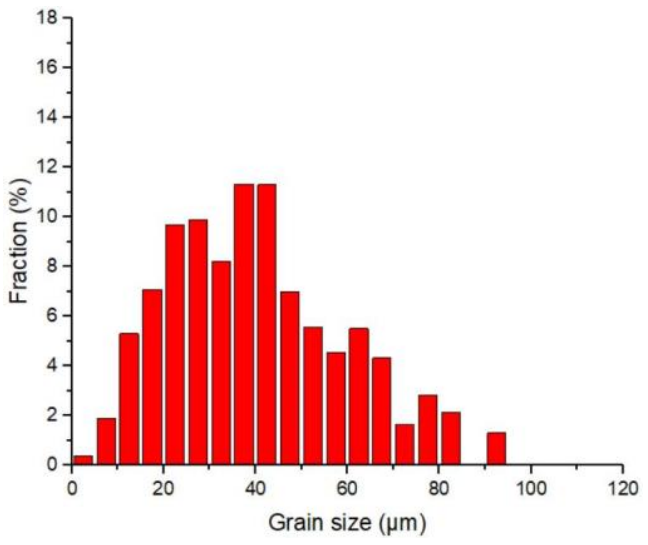

(f) $600 \mathrm{~s}$ of soaking after heating at $36{ }^{\circ} \mathrm{C} / \mathrm{s}$

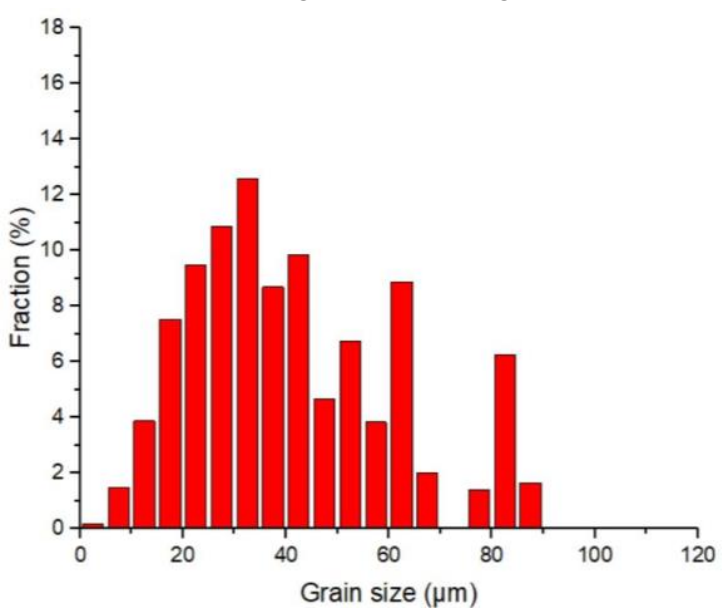

Fig. 8. The effects of heating rate and solution time on grain distribution 
With the increase of solution time to $25 \mathrm{~s}$, the average grain size appears to increase from approximately $15.8 \mu \mathrm{m}^{-2}$ at a soaking time of $1 \mathrm{~s}$ to approximately $21.4 \mu \mathrm{m}^{-2}$ (increased by $35 \%$ ) due to grain growth at elevated temperature, which caused the yield strength of the material to decrease from $284 \mathrm{MPa}$ to $275 \mathrm{MPa}$ (reduced 3.2\%). The increase of solution time from $25 \mathrm{~s}$ to $60 \mathrm{~s}$ resulted in the increase of $13 \%$ in grain growth and also the improvement of material yield strength. Although the grain size remains relatively stable between soaking time of $60 \mathrm{~s}$ and $600 \mathrm{~s}$, the material strength of AA6082 slightly increased. These observations are contrary to the predictions made by the Hall-Petch relationship, which suggests that the grain size and grain distribution are unlikely dominant factors that affect the strength of the material during the soaking process of SHT in HFQ.

\subsection{Effect of crystallographic texture on material strength}

Effects of microstructural evolution on material elongation, strength and formability are studied by researchers for various materials, such as titanium, aluminium and magnesium alloys [39-41]. Recrystallisation, occurred during heat treatment for AA6082, gave rise to distribution change of crystallographic orientations, and texture of the alloy was formed and observed in EBSD maps for most of the samples. The effect of texture on the material strength highly depends on the loading direction and overall orientation of the grains in the material [42]. In the CPFE model used in this study, material properties of each grain are identical and the calculated grain softness factor is dependent on the orientation and the loading direction. By using the equations presented in Section 3.3, the grain softness maps of the individual grains calculated are shown in Fig. 9, when loading direction being consistent with that of the uniaxial tensile test. High value of softness factor represent the soft grains and low value of softness factor represent the hard grains. These maps provide an overall information on material strength. Since the intragranular deformation tend to be non-uniform in soft grains, which will potentially increase heterogeneous intragranular dislocation density and thus localised strain/stress is more likely induced to occur [43, 44]. High percentage of soft grains in one softness map is likely to cause more plastic deformation, thus lower the strength of the material and might lead to early fracture during deformation. According to Fig. 9, the as-received material (Fig. 9 (a)) has a fairly random distribution of grain 
softness, while the textured materials, as shown in Fig. 9 (b)-(f), have relatively higher percentages of soft grains and hard grains.

(a) As-received material

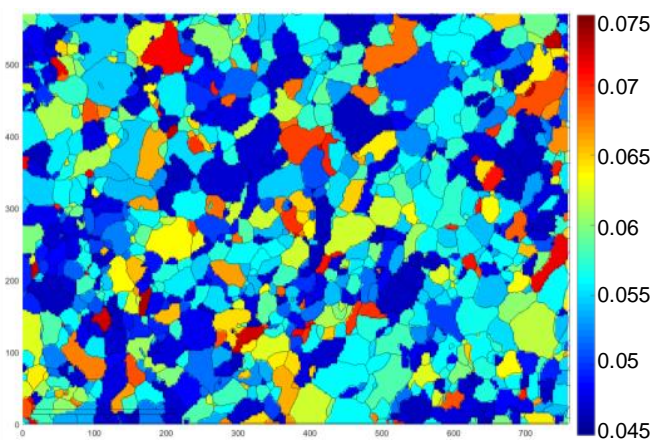

(c) $1 \mathrm{~s}$ of soaking after heating at $36^{\circ} \mathrm{C} / \mathrm{s}$

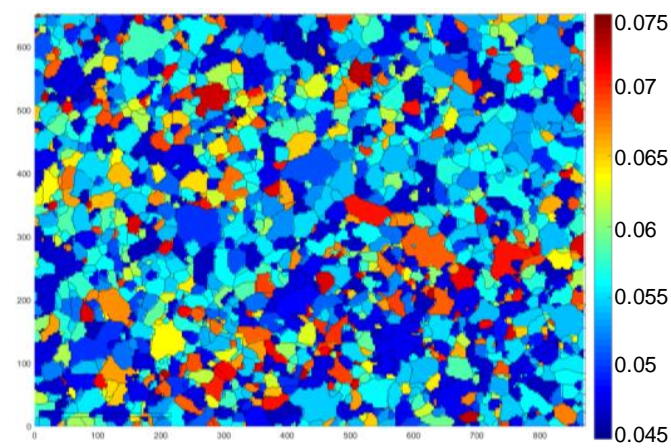

(e) $60 \mathrm{~s}$ of soaking after heating at $36^{\circ} \mathrm{C} / \mathrm{s}$

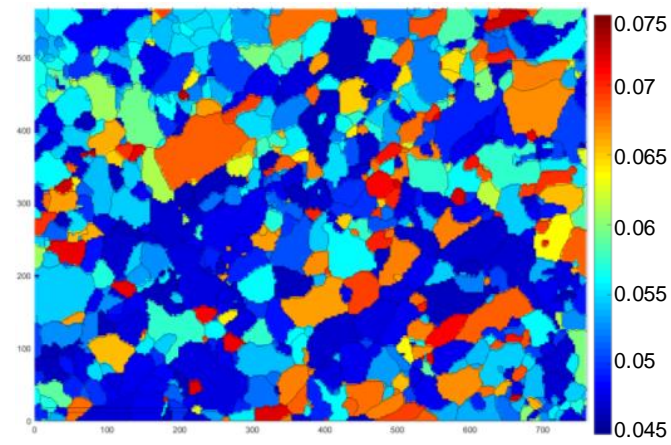

(b) $1 \mathrm{~s}$ of soaking after heating at $3{ }^{\circ} \mathrm{C} / \mathrm{s}$

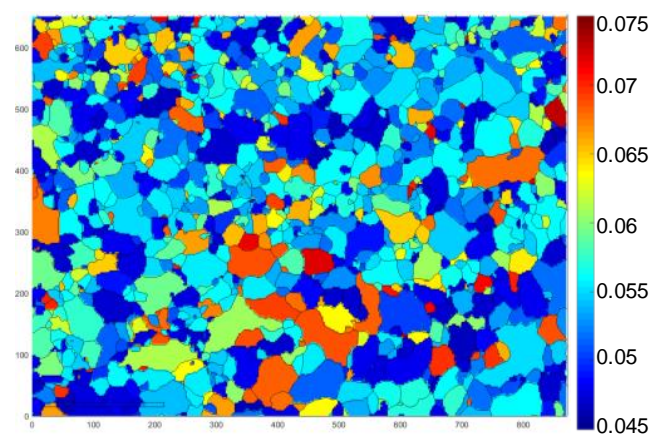

(d) $25 \mathrm{~s}$ of soaking after heating at $36^{\circ} \mathrm{C} / \mathrm{s}$

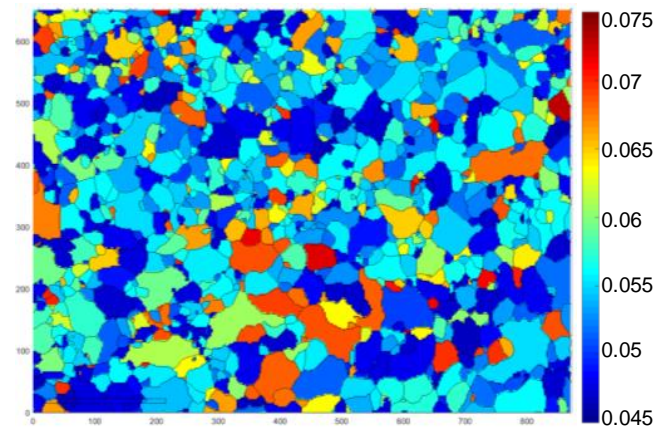

(f) $600 \mathrm{~s}$ of soaking after heating at $36^{\circ} \mathrm{C} / \mathrm{s}$

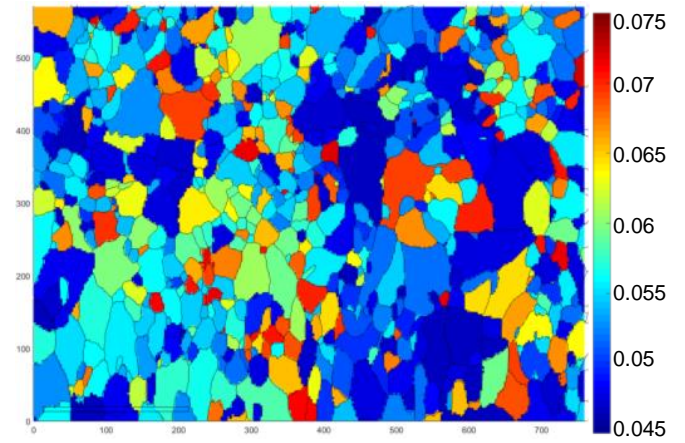

Fig. 9. The grain softness maps of the tested samples (High values represent soft grains, low values represent hard grains)

In order to quantify the effect of crystallographic texture, the probability density functions (PDF) [45] of grain orientations are plotted in the pole figures as shown in Fig. 10. The maximum PDF for the individual pole figure is used to quantify how strong of the material texture, and the grain orientation with the highest PDF, which is the dominant orientation, in the material can be identified and illustrated by the symbol of ' + ' in Fig. 10 for as-received material and each heat treatment condition. 
(a) As-received material

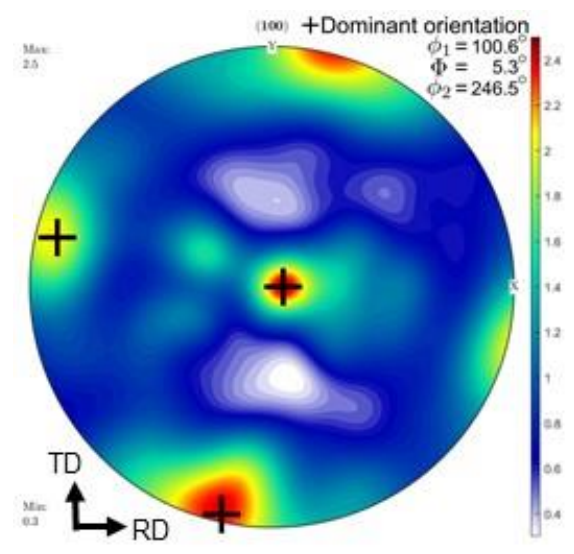

(c) $1 \mathrm{~s}$ of soaking after heating at $36^{\circ} \mathrm{C} / \mathrm{s}$

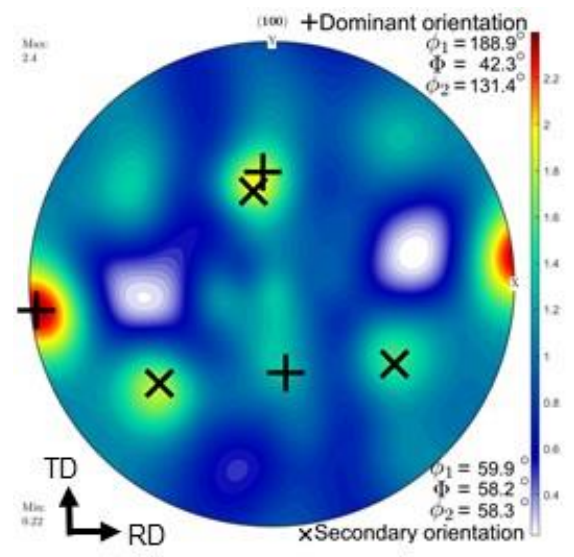

(e) $60 \mathrm{~s}$ of soaking after heating at $36^{\circ} \mathrm{C} / \mathrm{s}$

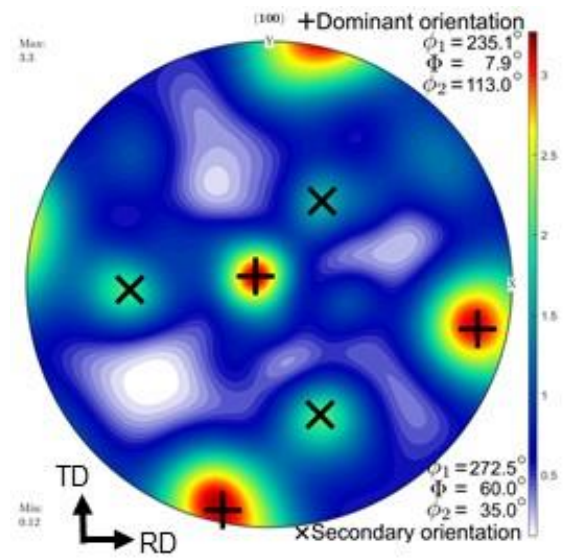

(b) $1 \mathrm{~s}$ of soaking after heating at $3{ }^{\circ} \mathrm{C} / \mathrm{s}$

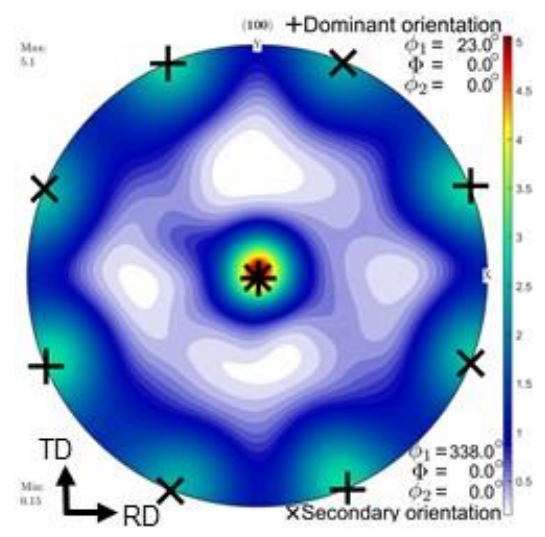

(d) $25 \mathrm{~s}$ of soaking after heating at $36^{\circ} \mathrm{C} / \mathrm{s}$

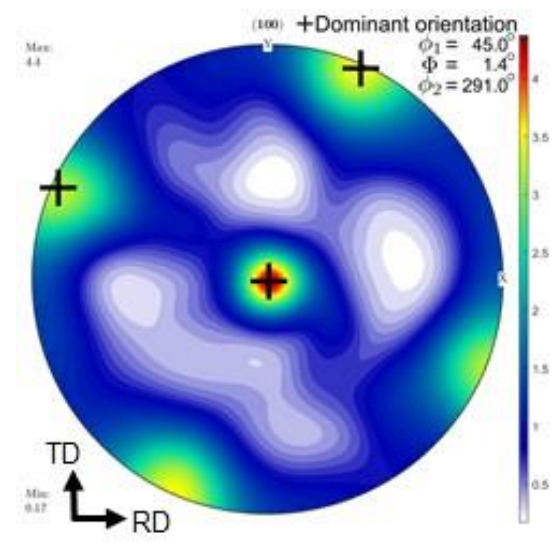

(f) $600 \mathrm{~s}$ of soaking after heating at $36^{\circ} \mathrm{C} / \mathrm{s}$

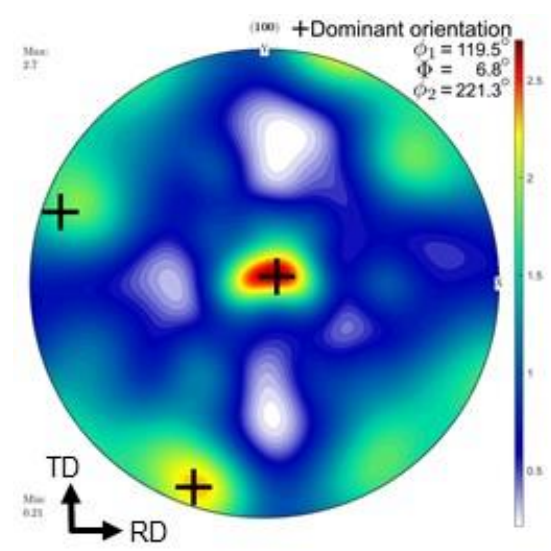

Fig. 10. Pole figures of the (100) showing the texture of the materials at different heat treatment conditions (' + ' represents dominant orientation, ' $x$ ' represents secondary orientation)

The maximum value of PDF calculated from the pole figures and the calculated softness factor of the dominant orientations are presented in Fig. 11. The maximum PDF of AA6082 heat treated at the slow heating rate of $3{ }^{\circ} \mathrm{C} / \mathrm{s}$ was two times higher than that 
at the high heating rate of $36^{\circ} \mathrm{C} / \mathrm{s}$, which indicates that high heating rate applied in heat treatment of the material can reduce the effect of texture. With the increase of the SHT time, the maximum value of PDF increased first and then decreased to the similar value of 2.7 as that of as-received material. The stronger the texture of the material, the more grains are oriented in the weaker direction, and therefore the lower the strength of the material. Since the dominant orientation of the heat treated materials is weaker than that of the as-received material, the yield strength of AA6082 decreased with increasing amounts of texture. This trend is consistent with that of the material strength at various solution times revealed in Fig. 6 (b). The grain softness of the dominant orientation appeared to be higher when the material was soaked for a certain time between $25 \mathrm{~s}$ and 600 s at SHT temperature of $535{ }^{\circ} \mathrm{C}$, which indicates that AA6082 had a preferred orientation of grains after heat treatment and caused lower strength of the material in the loading direction. This was also observed for slow heated samples. The softness paramter used in this paper is able to provide quantified effects of the grain orientation and the loading direction. Based on the analysis of the grain size and the texture, it is concluded that the texture plays a more significant role in determining the strength of the material than that of the grain size and grain distribution.

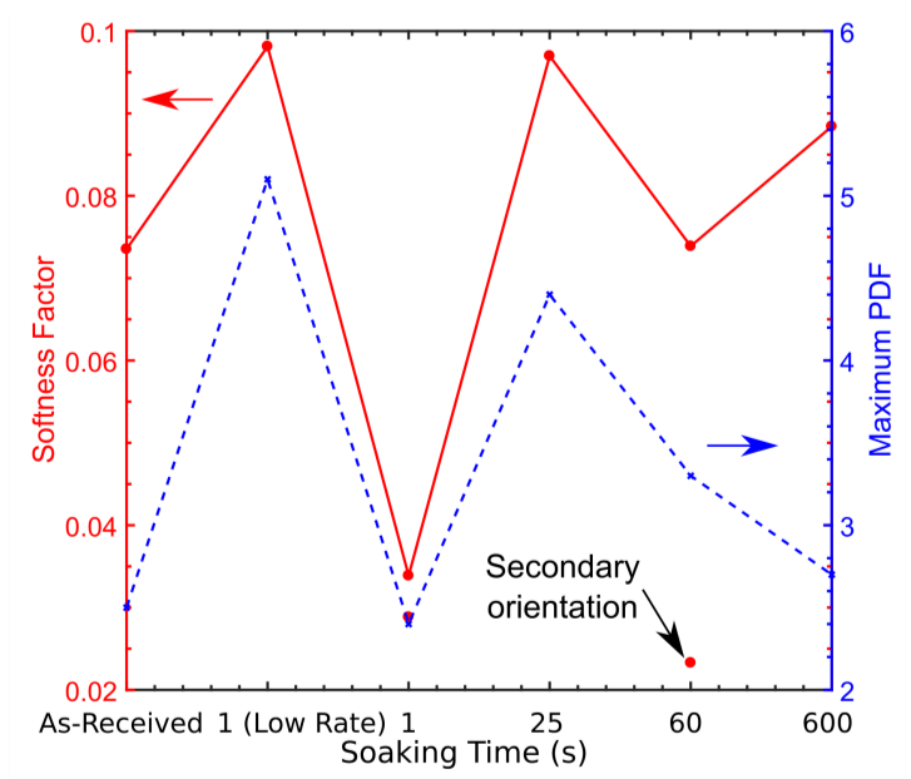

Fig. 11. Softness factor and the maximum value of PDF for different heat treatments.

\subsection{Effect of microstructure on localised deformation and ductility}

The CPFE model is able to capture material orientation and deformation behaviour of each individual grain, and can be used to investigate the effect of the microstructure 
evolution on the material ductility after various heat treatment processes. Strain maps with the presence of localised strain for AA6082 after heat treatment are shown in Fig. 12 , when the total strain in the loading direction at $2 \%$ overall strain of the stretching. These calculated strain fields provide a useful insight to study the deformation behaviour of AA6082 and the location with the high level of strain at the onset of yielding will potentially lead to material damage or facture, which determines the overall ductility of the material.

(a) As-received material

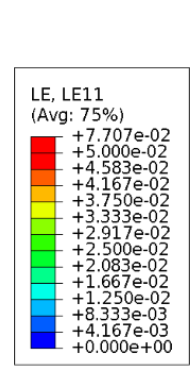

(c) $1 \mathrm{~s}$ of soaking after heating at $36^{\circ} \mathrm{C} / \mathrm{s}$

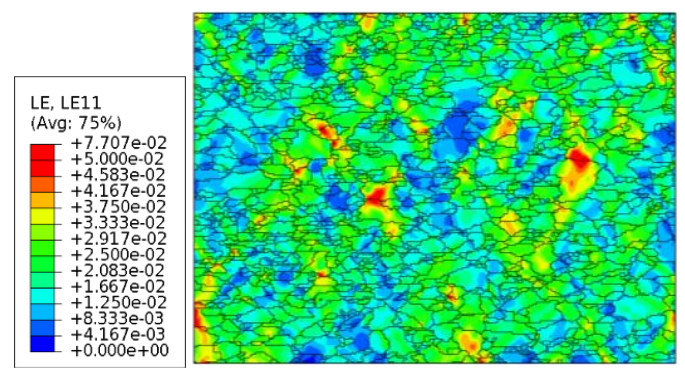

(e) $60 \mathrm{~s}$ of soaking after heating at $36{ }^{\circ} \mathrm{C} / \mathrm{s}$

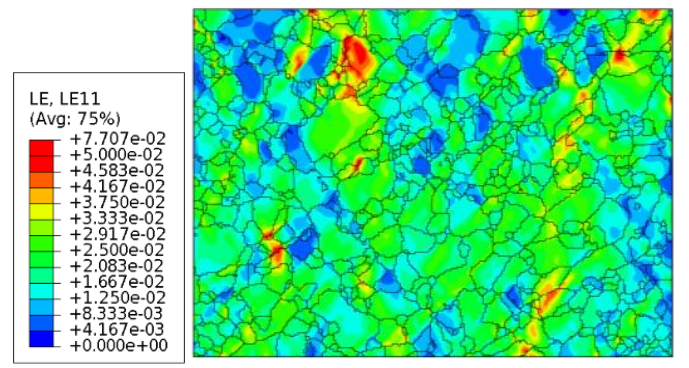

(b) $1 \mathrm{~s}$ of soaking after heating at $3{ }^{\circ} \mathrm{C} / \mathrm{s}$

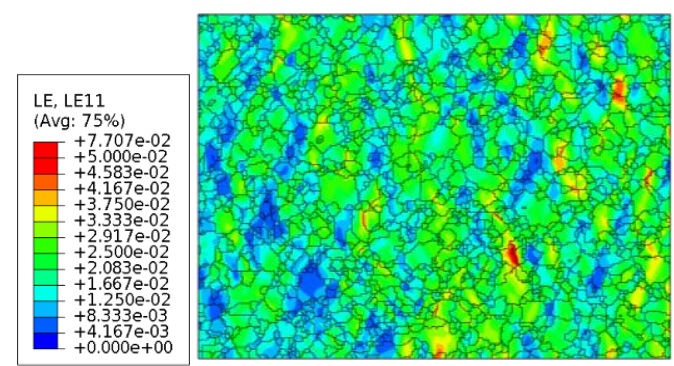

(d) $25 \mathrm{~s}$ of soaking after heating at $36^{\circ} \mathrm{C} / \mathrm{s}$

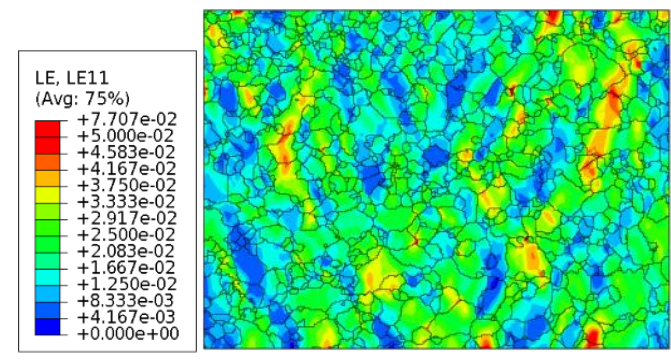

(f) $600 \mathrm{~s}$ of soaking after heating at $36^{\circ} \mathrm{C} / \mathrm{s}$

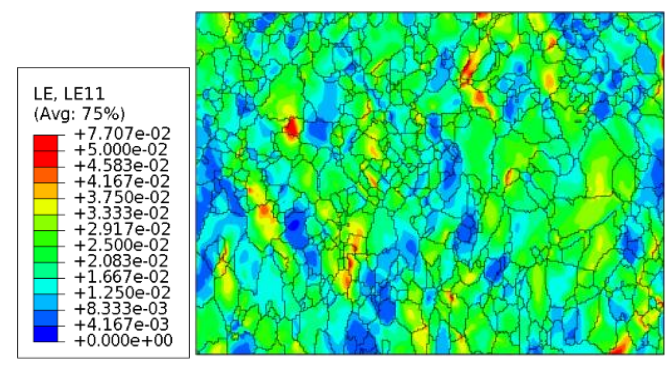

Fig. 12. Strain maps of AA6082 obtained from CPFE models at $2 \%$ overall strain (LE11 in the legend refers to the effective strain)

In this study, since the material fracture is usually resulted from accumulating damage, the mode of the localised strains, which indicates the most frequently occurrence of high strains, has been used to predict the ductility of AA6082 under various heat treatment conditions. Fig. 13 presents the values of the mode of strains calculated by 
CPFE models along with the ductility measured in the corresponding uniaxial tensile tests.

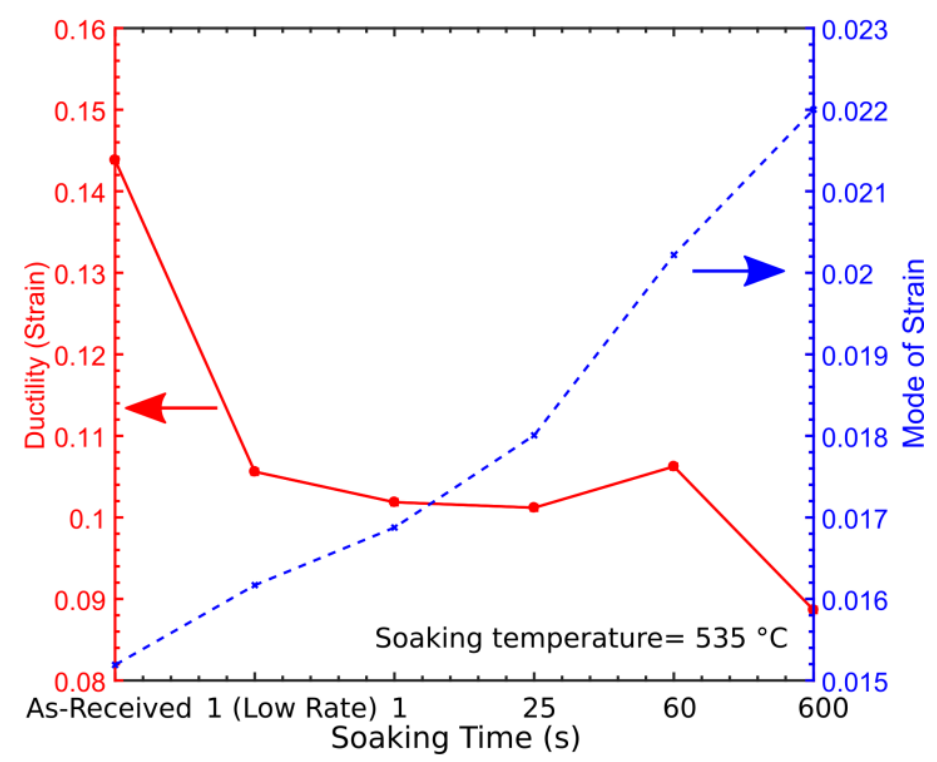

Fig. 13. Ductility and mode of strain after different heat treatment processes

It can be seen that the ductility of AA6082 has an inverse relationship with the mode of strains calculated from the CPFE models. The materials with crystallographic texture experienced a high amount of the localised deformation for softer grains, which led to material failure and thus a lower ductility. The AA6082 after SHT of $600 \mathrm{~s}$ with a low value of maximum PDF is not strongly textured, but with a large amount of soft grains which caused a high precentage of localised strains and thus a low ductility as observed in tensile test. Therefore, long soaking time in the heat treatment process has negative effect on the overall ductility of AA6082 due to both texture and the localised deformation caused by high percentage of soft grains, which could reduce the formability of the material in the HFQ process.

In summary, the developed CPFE model is able to quantify the material deformation response on a microstructural level and correlate the effects of grain microstructure and texture with the strength and the ductility of AA6082 under a range of HFQ conditions. For future work, the CPFE model will be developed further to incorporate the factor of damage in order to more accurately predict material mechanical behaviour and the effect of precipitate for the material. 


\section{Conclusions}

In this paper, in order to understand the deformation mechanism, optimise the heat treatment conditions and improve the heat treatment efficiency in HFQ processes, the effects of heating rate and soaking time at SHT temperature on the mechanical properties of AA6082 have been investigated at a microstructure level by using well established uniaxial tensile tests, EBSD microstructure characterisation and CPFE simulation. Compared to the slow heating in HFQ, rapid heating enables to improve the strength of AA6082 by $4 \%$, due to the reduction of texture, quantified by defined softness factor and PDF, and the decrease of average grain size of $17 \%$. The selected heat treatment processes were found to decrease the mechanical properties of AA6082 compared to the as-received state due to the recrystallisation i.e. the formation of more strain localised crystallographic texture with respect to the loading direction. At the SHT temperature of $535^{\circ} \mathrm{C}$, with the increase of solution time, the strength of AA6082 decreased by $3 \%$ first and then increased $4 \%$ due to the reduced texture in the material; however, the ductility of AA6082 reduced by up to $17 \%$ with increasing soaking time because of the high percentage of soft grains in the textured material and thus localised strains leading to material fracture. The CPFE simulation performed based on the obtained EBSD maps enables the deformation mechanism of AA6082 to be revealed and quantified. The obtained understanding of grain microstructure and texture and its associated strength and formability of the alloy can be used to enlarge the capability of HFQ for industrial applications.

\section{Acknowledgements}

Financial support from Innovate UK (Grant number: 102777) and the support of the RASTec partners (Impression Technologies Ltd., Imperial College London, Innoval Technology Ltd, Phoenix Calibration and Services Ltd.) for this research project is gratefully acknowledged by the authors. $\mathrm{HFQ}^{\circledR}$ is a registered trademark of Impression Technologies Limited. Impression Technologies Limited is the sole licensee for the commercialisation of the $\mathrm{HFQ}^{\circledR}$ technology from Imperial College London. 


\section{References}

[1] W.S. Miller, L. Zhuang, J. Bottema, A.J. Wittebrood, P. De Smet, A. Haszler, A. Vieregge, Recent development in aluminium alloys for the automotive industry, Materials Science and Engineering, 280 (2000) 37-49.

[2] D. Li, A. Ghosh, Tensile deformation behavior of aluminum alloys at warm forming temperatures, Materials Science and Engineering: A, 352 (2003) 279-286.

[3] Z. Shao, N. Li, J. Lin, T. Dean, Formability evaluation for sheet metals under hot stamping conditions by a novel biaxial testing system and a new materials model, International Journal of Mechanical Sciences, 120 (2017) 149-158.

[4] A. Foster, T.A. Dean, J. Lin, Process for forming aluminium alloy sheet component, patent no. WO2010032002A1, 2012.

[5] M.S. Mohamed, A.D. Foster, J. Lin, D.S. Balint, T.A. Dean, Investigation of deformation and failure features in hot stamping of AA6082: Experimentation and modelling, International Journal of Machine Tools and Manufacture, 53 (2012) 27-38. [6] O. El Fakir, L. Wang, D. Balint, J.P. Dear, J. Lin, T.A. Dean, Numerical study of the solution heat treatment, forming, and in-die quenching (HFQ) process on AA5754, International Journal of Machine Tools and Manufacture, 87 (2014) 39-48.

[7] Z. Shao, J. Jiang, J. Lin, Feasibility study on direct flame impingement heating applied for the solution heat treatment, forming and cold die quenching technique, Journal of Manufacturing Processes, 36 (2018) 398-404.

[8] J. Lin, T.A. Dean, A.D. Foster, L. Wang, D. Balint, A method of forming a component of complex shape from aluminium alloy sheet, patent no. WO2011/058332A1, 2011.

[9] R. Garrett, J. Lin, T. Dean, An investigation of the effects of solution heat treatment on mechanical properties for AA 6xxx alloys: experimentation and modelling, International Journal of Plasticity, 21 (2005) 1640-1657.

[10] Z. Shao, N. Li, J. Lin, T.A. Dean, Strain measurement and error analysis in thermomechanical tensile tests of sheet metals for hot stamping applications, Proceedings of the Institution of Mechanical Engineers, Part C: Journal of Mechanical Engineering Science, (2017) 095440621771401.

[11] Z. Shao, N. Li, J. Lin, T.A. Dean, Development of a New Biaxial Testing System for Generating Forming Limit Diagrams for Sheet Metals Under Hot Stamping Conditions, Experimental Mechanics, 56 (2016) 1489-1500.

[12] C. Poletti, M. Rodriguez-Hortalá, M. Hauser, C. Sommitsch, Microstructure development in hot deformed AA6082, Materials Science and Engineering: A, 528 (2011) 2423-2430.

[13] C.K.S. Moy, M. Weiss, J. Xia, G. Sha, S.P. Ringer, G. Ranzi, Influence of heat treatment on the microstructure, texture and formability of 2024 aluminium alloy, Materials Science and Engineering: A, 552 (2012) 48-60.

[14] X. Wang, M. Guo, A. Chapuis, J. Luo, J. Zhang, L. Zhuang, Effect of solution time on microstructure, texture and mechanical properties of $\mathrm{Al}-\mathrm{Mg}-\mathrm{Si}-\mathrm{Cu}$ alloys, Materials Science and Engineering: A, 644 (2015) 137-151.

[15] A.B. Lopes, F. Barlat, J.J. Gracio, J.F.F. Duarte, E.F. Rauche, Effect of texture and microstructure on strain hardening anisotropy for aluminum deformed in uniaxial tension and simple shear, International Journal of Plasticity, 19 (2003) 1-22.

[16] O.G. Lademo, K.O. Pedersen, T. Berstad, T. Furu, O.S. Hopperstad, An experimental and numerical study on the formability of textured $\mathrm{AlZnMg}$ alloys, European Journal of Mechanics - A/Solids, 27 (2008) 116-140. 
[17] Z. Marciniak, K. Kuczynski, Limit strains in the processes of stretch-forming sheet metal, International Journal of Mechanical Sciences, 9 (1967) 609-620.

[18] K.O. Pedersen, O.G. Lademo, T. Berstad, T. Furu, O.S. Hopperstad, Influence of texture and grain structure on strain localisation and formability for AlMgSi alloys, Journal of Materials Processing Technology, 200 (2008) 77-93.

[19] R. Shabadi, S. Suwas, S. Kumar, H.J. Roven, E.S. Dwarkadasa, Texture and formability studies on AA7020 Al alloy sheets, Materials Science and Engineering: A, 558 (2012) 439-445.

[20] P. Cavaliere, R. Nobile, F.W. Panella, A. Squillace, Mechanical and microstructural behaviour of 2024-7075 aluminium alloy sheets joined by friction stir welding, International Journal of Machine Tools and Manufacture, 46 (2006) 588-594. [21] Z. Gao, R.V. Grandhi, Microstructure optimization in design of forging processes, International Journal of Machine Tools and Manufacture, 40 (2000) 691-711.

[22] T.R. Prabhu, Effects of ageing time on the mechanical and conductivity properties for various round bar diameters of AA 2219 Al alloy, Engineering Science and Technology, an International Journal, 20 (2017) 133-142.

[23] S. Toros, F. Ozturk, I. Kacar, Review of warm forming of aluminum-magnesium alloys, Journal of Materials Processing Technology, 207 (2008) 1-12.

[24] K. Mori, S. Maki, M. Ishiguro, Improvement of product strength and formability in stamping of $\mathrm{Al}-\mathrm{Mg}-\mathrm{Si}$ alloy sheets having bake hardenability by resistance heat and artificial aging treatments, International Journal of Machine Tools and Manufacture, 46 (2006) 1966-1971.

[25] ISO Standard, Metallic materials - Tensile testing Part 1: Method of test at ambient temperature, ISO6892-1:2009.

[26] Y. Qin, N. Li, J. Zheng, C. Zhang, K. Zheng, J. Lin, T.A. Dean, T.A. Dean, J. Lin, S.J. Yuan, F. Vollertsen, Investigation on fast and energy-efficient heat treatments of AA6082 in HFQ processes for automotive applications, MATEC Web of Conferences, 21 (2015) 05015.

[27] F. Roters, P. Eisenlohr, L. Hantcherli, D.D. Tjahjanto, T.R. Bieler, D. Raabe, Overview of constitutive laws, kinematics, homogenization and multiscale methods in crystal plasticity finite-element modeling: Theory, experiments, applications, Acta Materialia, 58 (2010) 1152-1211.

[28] A. Ma, F. Roters, D. Raabe, A dislocation density based constitutive model for crystal plasticity FEM including geometrically necessary dislocations, Acta Materialia, 54 (2006) 2169-2179.

[29] L. Evers, Non-local crystal plasticity model with intrinsic SSD and GND effects, Journal of the Mechanics and Physics of Solids, 52 (2004) 2379-2401.

[30] F.P.E. Dunne, R. Kiwanuka, A.J. Wilkinson, Crystal plasticity analysis of microdeformation, lattice rotation and geometrically necessary dislocation density, Proceedings of the Royal Society A: Mathematical, Physical and Engineering Sciences, 468 (2012) 2509-2531.

[31] B. Chen, J. Jiang, F.P.E. Dunne, Microstructurally-sensitive fatigue crack nucleation in Ni-based single and oligo crystals, Journal of the Mechanics and Physics of Solids, 106 (2017) 15-33.

[32] R.J. Asaro, Crystal Plasticity, Journal of Applied Mechancis, 50 (1983) 921-934.

[33] A. Arsenlis, D.M. Parks, Crystallographic aspects of geometrically-necessary and statistically-stored dislocation density, Acta Materialia, 47 (1999) 1597-1611.

[34] J. Cheng, S. Ghosh, A crystal plasticity FE model for deformation with twin nucleation in magnesium alloys, International Journal of Plasticity, 67 (2015) 148-170. 
[35] H. Klein, R.A. Schwarzer, Texture Analysis with MTEX - Free and Open Source Software Toolbox, Solid State Phenomena, 160 (2010) 63-68.

[36] V. Randle, Electron backscatter diffraction: Strategies for reliable data acquisition and processing, Materials Characterization, 60 (2009) 913-922.

[37] P.D. Nicolaou, S.L. Semiatin, A.K. Ghosh, An analysis of the effect of cavity nucleation rate and cavity coalescence on the tensile behavior of superplastic materials, Metallurgical and Materials Transactions A, 31 (2000) 1425-1434.

[38] E.O. Hall, The Deformation and Ageing of Mild Steel: III Discussion of Results, Proceedings of the Physical Society. Section B, 64 (1951) 747-753.

[39] A. Orozco-Caballero, F. Li, D. Esqué-de los Ojos, M.D. Atkinson, J. Quinta da Fonseca, On the ductility of alpha titanium: The effect of temperature and deformation mode, Acta Materialia, 149 (2018) 1-10.

[40] R. Kumar, A. Gupta, A. Kumar, R.N. Chouhan, R.K. Khatirkar, Microstructure and texture development during deformation and recrystallisation in strip cast AA8011 aluminum alloy, Journal of Alloys and Compounds, 742 (2018) 369-382.

[41] L. Tang, F. Jiang, J. Teng, D. Fu, H. Zhang, Strain path dependent evolutions of microstructure and texture in AZ80 magnesium alloy during hot deformation, Journal of Alloys and Compounds, 806 (2019) 292-301.

[42] U. Kocks, C. Tomé, A.B. HR Wenk, Texture and anisotropy: preferred orientations in polycrystals and their effect on materials properties, Cambridge University Press, Cambridge, 1998.

[43] J. Jiang, T.B. Britton, A.J. Wilkinson, Mapping type III intragranular residual stress distributions in deformed copper polycrystals, Acta Materialia, 61 (2013) 58955904.

[44] J. Jiang, T.B. Britton, A.J. Wilkinson, Evolution of dislocation density distributions in copper during tensile deformation, Acta Materialia, 61 (2013) 72277239.

[45] S.H. Cha, Comprehensive survey on distance/similarity measures between probability density functions, International Journal of Mathematical models and Methods in Applied Sciences, 1 (2007) 300-307. 